\title{
Thermal Properties of Anionic Polyurethane Composition for Leather Finishing
}

\author{
Olga KOVTUNENKO ${ }^{1}$, Tatyana TRAVINSKAYA ${ }^{2}$, Olena MOKROUSOVA ${ }^{3}$ * \\ ${ }^{1}$ Kiev National University of Design and Technology, Nemirovicha-Danchenko, 2, Kiev 01011,Ukraine \\ ${ }^{2}$ Institute of Macromolecular Chemistry, NAS of Ukraine, Kharkovskoe shosse 48, Kiev 02160, Ukraine \\ ${ }^{3}$ Kiev National University of Trade and Economics, Kioto 119, Kiev 02156, Ukraine
}

cross $^{\text {ref }}$ http://dx.doi.org/10.5755/j01.ms.22.3.10043

\section{Received 23 February 2015; accepted 14 July 2015}

\begin{abstract}
Thermal properties of anionic polyurethane composition mixed with collagen product and hydrophilic sodium form of montmorillonite for use in the finishing of leather were studied by thermogravimetric method. The thermal indices of processes of thermal and thermo-oxidative destruction depending on the polyurethane composition were determined. The influence of anionic polyurethane composition on thermal behavior of chromium tanned gelatin films that imitate the leather were studied. APU composition with natural compounds increases their thermal stability both in air and in nitrogen atmosphere due to the formation of additional bonds between active groups of APU, protein and chrome tanning agent as the result of chemical reactions between organic and inorganic parts with the new structure formation. Keywords: anionic polyurethane, composition, collagen products, montmorillonite, thermal stability, leather, finishing.
\end{abstract}

\section{INTRODUCTION}

A large number of modified compositions are used for finishing leather, which allows to obtain coatings with high technological and consumer characteristics. The properties of finishing coatings on the leather depend primarily on the properties of film forming matter used, which are applied for the leather coating [1].

Modern resource-saving production technology and leather finishing include the use of natural polymers of animal and plant origin [2]. As well except availability and safety, they are usually biodegradable that substantially reduces the cost of waste disposal and recycling. Mixing of synthetic polymers with natural ones is one of the simplest and most effective methods of modifying their properties [3].

The use in compositions for leather finishing of collagen products (CP) can significantly increase the adhesion of the coating, resistance to multiple flexing and dry friction, thermomechanical stability, without impairing the rigidity [4]. However, the properties of composite polymeric materials depend not only on choosing of their constituents, but also on the nature of the interaction between them in the technological process.

Polymer materials modified with nanosized particles layered silicates have a number of significant advantages. When introducing montmorillonite into the polymeric matrix, there is an increased in modulus of elasticity, strength, increased thermal stability and reduction of water vapor permeability of material $[5,6]$.

Interesting in this respect is receiving the new film forming matter using the modifications of dispersions of polyurethane anionomers (APU) in an aqueous solution of a collagen product with a use of hydrophilic sodium form montmorillonite (Na-MMT) for forming composites from

\footnotetext{
* Corresponding author. Tel.: +38-050-4639597.

E-mail address: mokrousovaolena@mail.ru (O. Mokrousova)
}

the aqueous dispersions used in the leather finishing. The combination of useful properties of such materials is an important practical task.

Polyurethane ionomers are obtained by method of emulsion polymerization, are characterized by a number of properties of the materials obtained in the block and in the solution, which are connected to conformational characteristics of macromolecules, a molecular weight and the presence of ionic centers in the macromolecules chain. The ability of APU spontaneously dispersible to form stable aqueous dispersions, is their principal advantage compared with traditional polyurethanes (PU) in organic solvents. Furthermore, the introduction of ionic groups in the structure of the hydrophobic PU leads to a significant change of properties of the latter (the glass transition temperature of physico-mechanical properties, the degree of hydrophilicity) [7].

Based on their chemical structure and method for obtaining modified APU, it is apparent that the structure and properties of such polymeric materials are determined by the relation and the degree of compatibility of the components, the distribution of the intra- and intermolecular bonds within the polymer chain

In the process of coating formation the coating agents, in particular a solvent and film forming matter, more or less diffuse inside the derma. The depth of their permeation depends on the state of the leather surface and on the properties of coating composition.

As the result of such diffusion, the polymer agent should make a certain impact on the leather and form particular bonds inside of the dermis structure. The interaction between a reactive groups in the polymer and the active centers in the dermis structure must lead to change of the properties of the semi-finished item and finished leather. This hypothetical interaction will also influence the thermal stability of facial layer of the leather and cover film. So, the main aim of this work was to study the influence of APU composition on the physical and 
chemical conversion of surface of leather and its thermal resistance by studying the process of destruction of gelatin films, anionic polyurethane composition.

\section{EXPERIMENTAL}

\subsection{Materials and preparation}

As the objects we used the film of chromium tanned gelatin (CG) - derma pattern, sample $1^{*}$; original APU, sample 2; APU mixed with CP, samples 3, 3"; APU mixed with $\mathrm{CP}$ and $\mathrm{Na}-\mathrm{MMT}$, samples 4, 4"; and the film of CG, mixed with APU and CP, sample 5 (Table 1).

Table 1. The composition of studied samples and conditions of TGA analysis

\begin{tabular}{|l|c|c|c|c|}
\hline $\begin{array}{c}\text { Sample } \\
\text { № }\end{array}$ & \multicolumn{3}{|c|}{ Sample composition } & $\begin{array}{c}\text { Conditions of TGA } \\
\text { analysis }\end{array}$ \\
\hline $1^{*}$ & CG & - & - & Air atmosphere \\
\hline 2 & APU & - & - & Air atmosphere \\
\hline 3 & APU & CP & - & Air atmosphere \\
\hline $3 "$ & APU & CP & - & Nitrogen atmosphere \\
\hline 4 & APU & CP & Na-MMT & Air atmosphere \\
\hline $4 "$ & APU & CP & Na-MMT & Nitrogen atmosphere \\
\hline 5 & CG & APU mixed with CP & Air atmosphere \\
\hline
\end{tabular}

Gelatine of SER "Lisichanskiy Gelatin Factory" (Ukraine) was used for the investigation. The properties of gelatin (GOST 11293-89): particle size < $5 \mathrm{~mm}$; $\mathrm{pH}$ in soluble state in amount of $1.0 \%=5.6 \pm 0.1 \%$, protein content $=83.32 \pm 0.03 \%$; ash $=1.38 \pm 0.01 \%$; moisture content $=15.3 \pm 0.1 \%$.

The derma pattern (CG) was prepared as follows: the solution $(5 \%)$ of eatable gelatin was treated during the 3 hours with chromium (III) salts in the quantity of $3.0 \%$ $\mathrm{Cr}_{2} \mathrm{O}_{3}$ counting on dry protein at the temperature of $20 \pm 2{ }^{\circ} \mathrm{C}$.

The anionic polyurethane added into the solution chromium tanned gelatin in the quantity of $20 \%$ counting on dry substance at the temperature $20 \pm 2{ }^{\circ} \mathrm{C}$. The films with the thickness of $100 \mu \mathrm{m}$ were formed by pouring on the Teflon disks, with following drying at room temperature for 72 hours, and then in the oven at $60{ }^{\circ} \mathrm{C}$ till constant weight.

Bentonite clays of Dashukovskogo deposition (Ukraine) was used for the investigation. The content of montmorillonite in bentonite rocks constituted $85 \%$. Montmorillonite dispersion was modified by sodium carbonate. For that, sodium carbonate in soluble state in amount of $10.0 \%$, depending on mineral weight, was introduced into water dispersion with montmorillonite concentration of $50 \mathrm{~g} / \mathrm{l}$. The obtained dispersion (Na-MMT) was mixed for 120 minutes and further it was used for mixed with APU. The content of Na-MMT in the anionic polyurethane constituted $1.8 \%$ in amount dry PU.

\subsection{Characterization techniques}

Dynamic thermogravimetric analysis TGA of modified APU and gelatin films was carried out using the device NETZSCH-Gerätebau GmbH TG 209 F1 Libra ${ }^{\circledR}$ with Proteus ${ }^{\circledR}$ Software in the nitrogen and air atmosphere (Table 1) at the temperature rate of $20{ }^{\circ} \mathrm{C} / \mathrm{min}$, the final temperature was $700{ }^{\circ} \mathrm{C}$. Sample weight amounted to $500 \mathrm{mg}$. Thermo- and thermooxidative stability of the samples was determined according to the temperature and thermogravimetric characteristics [7], obtained during dynamic thermogravimetric analysis.

The following characteristics were studied: mass/temperature, temperatures of mass losses at the beginning and the end of samples' decomposition, the stages of the mass changes, \% of mass change $(\Delta m)$, temperature of the first and second derivatives maxima on thermogravimetric curve, and coce-residue.

For the well distinguishable and partially overlapped decomposition stages the activation energies have been calculated using Broido method [8].

\section{RESULTS AND DISCUSSION}

The oxidative destruction can be differentiated by its low selectivity due to the free radical mechanism. As the result, during the oxidation of oxygen-containing polymers along with the valence bonds of macromolecular chain the functional groups and $\mathrm{C}-\mathrm{H}$ bonds are affected. The higher the molecular mass of polymer, the greater the level of oxidation destruction. The intensity of the process increases under the influence of high temperature, promoting the oxygen activation and, therefore, the diffusion rate into the polymer increases.

The process of thermal destruction of polymers represents a set of homogeneous and heterogeneous chemical reactions and phase transformations usually accompanied by heat absorption and decreasing molecular mass due to release of volatile decomposition products. The reaction is accelerated by substances, easily decomposing into free radicals. A characteristic feature of this type of destruction is that it leads not only to reduce the degree of polymerization and the change of the macromolecule structure, but also to the depolymerization.

Start decomposition temperature, mass loss $(\Delta m)$ at the temperature of maximum decomposition rate $\left(T_{\max }\right)$, the value of coke residue, the maximum decomposition rate (Table 2) and effective activation energy (Table 3) have been determined from the thermograms (Fig. 1, Fig. 2) of the original APU (sample 2), chromium tanned gelatin (sample $1 *$ ) and compositions (samples 3, 4, 5). As shown in Table 2, Fig. 2, the mass drop of all samples passes through the several stages of differing intensities, which reflect the progress of the chemical and physical transformations of film forming matter, when heated in air atmosphere (Fig. 2 a) and nitrogen atmosphere (Fig. 2 b). The number of stages of decomposition, the ratio of their intensities and the temperature range of stages depends on the components.

\subsection{Thermo-oxidative destruction of chromium tanned gelatin}

The nature of TG curves is similar for all films, except for the sample $1^{*}$ chromium tanned gelatin (Fig. $1 \mathrm{c}$ ). Thermal destruction of $\mathrm{CG}$ is finished at $794{ }^{\circ} \mathrm{C}$ and represents a multistep process of transformation: first modified collagen and after $400{ }^{\circ} \mathrm{C}$-chromium complex with the final oxidation of the intermediate products to the chromium oxide $[9,10]$. 


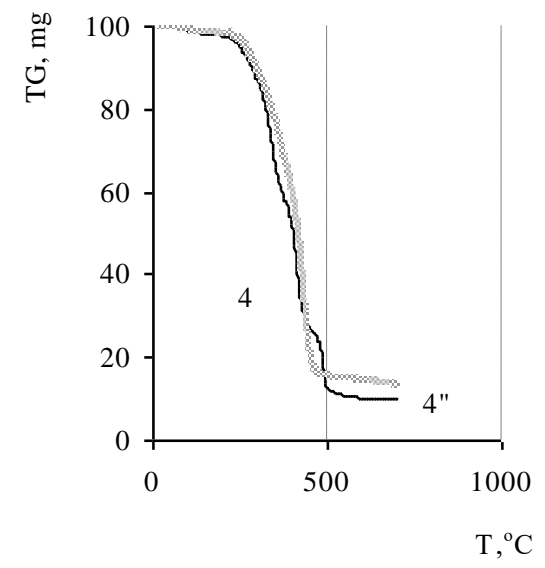

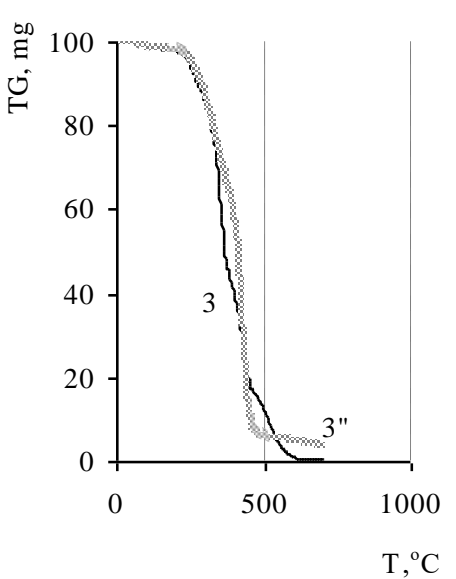

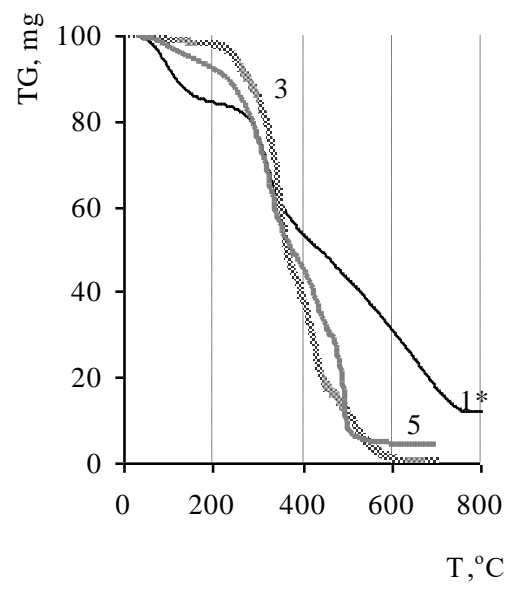

Fig. 1. Thermogravimetric curves of the samples (the numbers of the samples comply with Table 1)

As you can see, thermal destruction of CG films can be divided into four main stages (Fig. $1 \mathrm{c}$, Table 3).If we compare the passage of the thermal transformations of CG with the native protein (melting, transition to the viscous state, and the thermal decomposition: 130,230 and $270{ }^{\circ} \mathrm{C}$, correspondingly $[11,12,13]$, we can trace the shift of some DTG peaks of CG (Fig. 2 a) to the high temperature range, due to structuring effect of tanning chromium compounds. By analyzing DTG data and the results of their treatment (Table 2, and Table 3, sample $1 *$ ), we note that the low-temperature decomposition stage of CG (69$129^{\circ} \mathrm{C}$ ) is connected with evaporation of mechanically and adsorptive bounded water during the heating. The sample loses about $9.4 \%$ weight at the peak of $85{ }^{\circ} \mathrm{C}$. At this stage the possible rearrangement of chromium complexes and removal of water molecules from the inner coordination sphere of the complex with the formation of additional bonds between the protein and tanning agents is taking place $[13,14]$. This assumption is supported by substantial $E_{\text {akt }}$ at this stage, which is $74 \mathrm{~kJ} / \mathrm{mol}$. In the $130-260{ }^{\circ} \mathrm{C}$ temperature range (Fig. 2, curve $1 *$ ) no significant decrease in the mass of the sample is observed, which indicates the ongoing of physical processes of melting of amorphous and then of crystalline zones of gelatin and its transition to a plastic viscous state.

The third stage that is in the temperature range $\left(244-354{ }^{\circ} \mathrm{C}\right)$ is characterized by an intense process of decomposition, significant mass loss (up to $20.1 \%$ ) with a

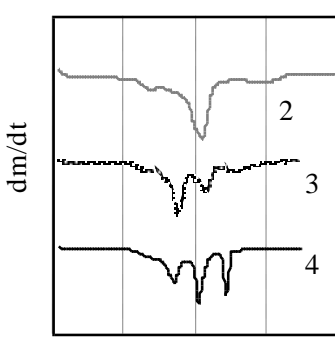

$0 \quad 200 \quad 400 \quad 600 \quad 800$

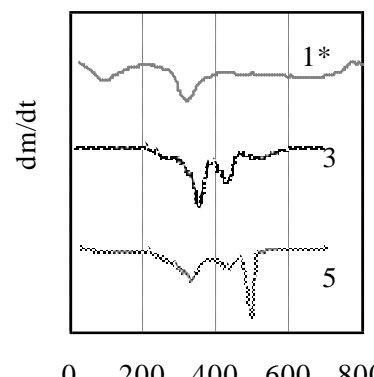

$\mathrm{T},{ }^{\circ} \mathrm{C}$

$\mathrm{T},{ }^{\circ} \mathrm{C}$

a

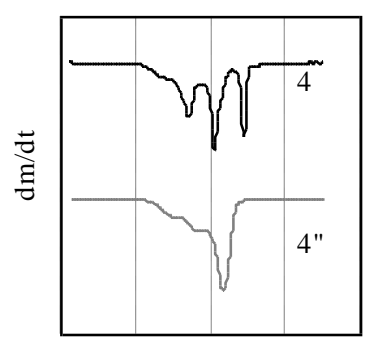

$\begin{array}{lllll}0 & 200 & 400 & 600 & 800\end{array}$

$\mathrm{T},{ }^{\circ} \mathrm{C}$

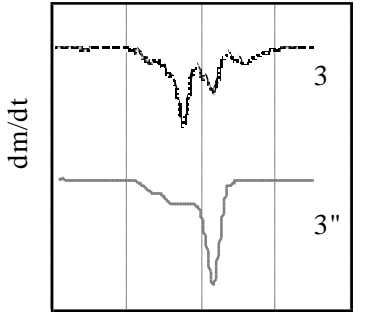

$\begin{array}{lllll}0 & 200 & 400 & 600 & 800\end{array}$

$\mathrm{T},{ }^{\circ} \mathrm{C}$

b

Fig. 2. DTG curves of samples: $a$-in the air atmosphere; $b$-in the nitrogen atmosphere (the numbers of the samples comply with Table 1) 
Table 2. Results of thermo- (3", 4") and thermooxidative $(1 *, 2,3,4,5)$ destruction

\begin{tabular}{|l|c|c|c|c|c|c|c|}
\hline Sample & Components & $\begin{array}{c}T_{\text {start }} \text { decompos., } \\
{ }^{\circ} \mathrm{C}\end{array}$ & $T_{\text {end, }}{ }^{\circ} \mathrm{C}$ & $\begin{array}{c}T_{\text {max.. }} \\
\text { decompos., }\end{array}$ & $\begin{array}{c}\text { Max rate of decompos., } \\
\text { dm/dt, mg/min }\end{array}$ & $\begin{array}{c}\text { Mass loss, \%, at } \\
T_{\text {max. }} \text { decompos. }\end{array}$ & $\begin{array}{c}\text { Coke- } \\
\text { residue, } \%\end{array}$ \\
\hline $1^{*}$ & CG & 244 & 794 & 317 & 0.8 & 20.1 & 12.08 \\
\hline 2 & - & 185 & 640 & 416 & 1.7 & 29.9 & 0.03 \\
\hline 3 & CP & 264 & 700 & 349 & 1.34 & 25.2 & 0.49 \\
\hline $3 "$ & CP & 279 & 700 & 432 & 3.0 & 41.3 & 3.79 \\
\hline 4 & CP + Na-MMT & 308 & 700 & 408 & 2.27 & 18.2 & 9.96 \\
\hline $4 "$ & CP + Na-MMT & 308 & 700 & 432 & 2.53 & 32.9 & 13.45 \\
\hline 5 & CP + CG & 294 & 700 & 497 & 1.17 & 16.9 & 4.4 \\
\hline
\end{tabular}

Table 3. Activation energy and weight loss during thermodestructive stages

\begin{tabular}{|c|c|c|c|c|c|c|c|c|c|c|}
\hline \multirow{2}{*}{ Sample } & \multicolumn{5}{|c|}{ Temperature range $\Delta T,{ }^{\circ} \mathrm{C} /$ mass $\operatorname{loss} \Delta m, \%$ at $T_{\max }$ according to stages } & \multicolumn{5}{|c|}{$E_{\text {act }}, \mathrm{kJoule} / \mathrm{mol}$} \\
\hline & $\mathrm{I}$ & II & III & IV & $\mathrm{V}$ & $\mathrm{I}$ & II & III & IV & $\mathrm{V}$ \\
\hline $1 *$ & $\begin{array}{c}69-129 / \\
85 ; 9.36\end{array}$ & - & $\begin{array}{c}244-354 / \\
317 ; 20.1\end{array}$ & $\begin{array}{c}462-477 / \\
470 ; 1.74 \\
\end{array}$ & $\begin{array}{c}656-744 / \\
666 ; 3.25\end{array}$ & 74 & - & 80 & 31 & 71 \\
\hline 2 & $\begin{array}{l}62-110 / \\
71 ; 0.88 \\
\end{array}$ & $\begin{array}{c}185-230 / \\
208 ; 3.0 \\
\end{array}$ & $\begin{array}{l}260-287 / \\
272 ; 5.95 \\
\end{array}$ & $\begin{array}{c}403-430 / \\
416 ; 29.9 \\
\end{array}$ & $\begin{array}{l}576-608 / \\
598 ; 3.25 \\
\end{array}$ & 56 & 65 & 108 & 220 & 97 \\
\hline 3 & $\begin{array}{l}62-114 / \\
84 ; 0.97\end{array}$ & $\begin{array}{c}237-272 / \\
264 ; 5.3\end{array}$ & $\begin{array}{c}332-367 / \\
349 ; 25.2\end{array}$ & $\begin{array}{c}414-447 / \\
432 ; 14.8\end{array}$ & $\begin{array}{c}492-559 / \\
492 ; 10.1\end{array}$ & 72 & 132 & 183 & 31 & 91 \\
\hline 3" & $\begin{array}{l}62-147 / \\
92 ; 0.74 \\
\end{array}$ & $\begin{array}{l}279-344 / \\
327 ; 15.8 \\
\end{array}$ & - & $\begin{array}{c}410-452 / \\
432 ; 41.5\end{array}$ & - & 70 & 117 & - & 269 & - \\
\hline 4 & $\begin{array}{c}73-120 / \\
95 ; 0.98 \\
\end{array}$ & - & $\begin{array}{l}308-355 / \\
340 ; 20.9 \\
\end{array}$ & $\begin{array}{c}400-425 / \\
408 ; 18.2 \\
\end{array}$ & $\begin{array}{c}480-495 / \\
488 ; 9.3 \\
\end{array}$ & 69 & - & 147 & 193 & 213 \\
\hline 4" & $\begin{array}{l}72-122 / \\
95 ; 0.71\end{array}$ & - & $\begin{array}{c}315-382 / \\
367 ; 20.3\end{array}$ & $\begin{array}{c}415-455 / \\
432 ; 32.9\end{array}$ & - & 61 & - & 119 & 221 & - \\
\hline 5 & $\begin{array}{l}79-119 / \\
99 ; 2.36 \\
\end{array}$ & - & $\begin{array}{l}294-354 / \\
332 ; 23.3 \\
\end{array}$ & $\begin{array}{c}414-449 / \\
434 ; 9.82 \\
\end{array}$ & $\begin{array}{c}484-507 / \\
497 ; 16.9 \\
\end{array}$ & 69 & - & 101 & 68 & 330 \\
\hline
\end{tabular}

According to the literature [15], the weakest in the polyurethanes is polyurethane bond, and thus thermal destruction in the temperature range $\left(185-230^{\circ} \mathrm{C}\right.$, stage II) with a mass loss of $3 \%$ begins with the decay of the $\mathrm{C}-\mathrm{N}$ bond in the urethane group - $\mathrm{NH}-\mathrm{CO}-\mathrm{O}-$ with the release of $\mathrm{CO}_{2}$ and a low energy $\mathrm{E}_{\mathrm{act}}=65 \mathrm{~kJ} / \mathrm{mol}$. The third stage of the destructive process with a peak of $272{ }^{\circ} \mathrm{C}$ shows a gap of valence bonds and the formation of molecular fragments (gassing) and means the recombination of the valence bonds or the formation of new more heat-resistant compounds. The process of destruction proceeds with the loss of weight of $5.95 \%$ and an $E_{\text {act }}=108 \mathrm{~kJ} / \mathrm{mol}$.

The maximum mass loss rate $1.7 \mathrm{mg} / \mathrm{min}$ of the original APU (Fig. 2 a, curve 2) is observed at the IV stage at $416{ }^{\circ} \mathrm{C}$, which is $29.9 \%$ by weight of the sample. The energy of bond rupture is the highest, $E_{\text {act }}=220 \mathrm{~kJ} / \mathrm{mol}$. We can assume that at this stage the APU destruction accompanied by oxidation processes formation of intermediate products and the release of the gas phase [16] is taking place.

The processes occurring in the last stage of APU decomposition, with a peak $598{ }^{\circ} \mathrm{C}$ and negligible mass loss of $3.25 \%$, are related to the oxidative destruction of the carbon skeleton, accompanied by a great amount of heat energy. The effective activation energy is $97 \mathrm{~kJ} / \mathrm{mol}$.

\subsection{Thermo-oxidative destruction of APU compositions}

Lowering of the samples $(3,4)$ mass during the first stage $62-114{ }^{\circ} \mathrm{C}$ and $73-120^{\circ} \mathrm{C}$, correspondingly, is the result of loss of crystallization water, Table 3 , Fig. 2 a. The heat resistance of the samples 3 and 4 is increased due to the presence in the system of polyurea (curve 3, stage II, III) and the product of the interaction of organic and inorganic components with formation of urethane-like structures: SiO...H-C, Si-O-C, R-COO-Na-Si (curve 4, stages III, IV).

The introduction of $\mathrm{CP}$ to APU provides some thermal stabilization on the second stage of destruction, shifting the temperature peak by $56{ }^{\circ} \mathrm{C}$ to the higher temperature range in comparison with the original APU (Fig. 2 a, curve 3, Table 3).

The start decomposition temperature in the air atmosphere of APU composition with $\mathrm{CP}$ is higher by $79^{\circ} \mathrm{C}$ in comparison with original APU (Table 2, sample 3), and it loses more weight, which, together with significantly increasing (almost twice) activation energy of the second and third stage of decomposition (Table 3), confirms the fact of the chemical modification of anionic polyurethane with collagen product. Taking into account the high chemical activity of the $\mathrm{CP}$, we can assume that, like collagen, a product of its hydrolysis can react with the polyurethane ionomer, forming all possible types of bonds from van der Waals to covalent [12].

The APU composition with montmorillonite starts to decompose at the temperature on $120{ }^{\circ} \mathrm{C}$ higher than the analogue of the organic APU. Its coke residue is about $10 \%$, while the original APU burns almost completely. In sample 4, modified with Na-MMT, at the third stage (the temperature range of $308-355^{\circ} \mathrm{C}$ ) the rupture of molecule skeleton is taking place, passing through $\mathrm{Si}-\mathrm{O}-\mathrm{C}$ bond, the cohesion energy of which is lower then that of -C-C - and - $\mathrm{Si}-\mathrm{Si}-$, followed by the formation of siloxane structures [17]. Simultaneously the oxidative processes of carbohydrate degradation products decomposition, accompanied by large exothermic effects and the highest 
rate of degradation $(2.27 \mathrm{mg} / \mathrm{min})$ are passing. Two subsequent steps in the ranges $400-425^{\circ} \mathrm{C}$ and

$480-495^{\circ} \mathrm{C}$ are characterized by a lower rate of degradation and the increased values of the effective activation energy. The complexity of the process of thermal decomposition may be the result of the addition of layered silicate which acts as the initiator of coke formation due to the barrier effects with respect to the volatile products. As well the complexity is caused by other phenomena associated with a change in the entropy of macromolecular chains of the subsurface layer of the nanocomposites.

Obviously, in this case the structural features of filled polymer become apparent: on one hand the loosening of the polymer structure, which helps to increase oxygen diffusion into the polymer and the activation of oxidation of modified APU, on the other - the strong catalytic effect of the oxide surface on the boundary polymer - Na-MMT. It can be assumed that the introduction of inorganic fragments into the structure of APU is accompanied with the change in the nature and rate of thermal destruction processes due to several reasons, foremost among which is the change in energies of bond dissociation as a result of additional interactions (Van der Waals, hydrogen, etc.) with the products of thermal degradation.

\subsection{Thermodestruction of APU compositions}

DTG curves taken in a nitrogen atmosphere (Fig. 2 b, Table 1 - Table 3, sample 3", 4") differ from the curves taken in air. Number of process stages is reduced from five to three, which means that the oxidation processes have a significant impact on degradation of modified APU. The second stage of decomposition of the sample 3 " is shifted to higher temperatures by an average of $50{ }^{\circ} \mathrm{C}$ (Table 3 ), and the energy of bonds-braking is reduced by $15 \mathrm{~kJ} / \mathrm{mol}$. The peak of the maximal rate of decomposition is also shifted with a significant increase of $E_{\text {act }}$ for this stage.

TG-curves (Fig. 1 b), DTG curves (Fig. 2 b) and the data (Table 2, Table 3) for the organosilicone sample 4" in atmosphere of nitrogen and air, have a similar character. The beginning of thermodestruction in nitrogen atmosphere shifts to the higher temperatures of $7{ }^{\circ} \mathrm{C}$ compared to the thermo-oxidative destruction of the sample. Peak of the maximum rate of sample decomposition is moved to a high temperature mode with increasing the amount of carbon residue (Table 2 ).

Thus, it is shown that mixed anionic polyurethane with natural compounds, used for leather finishing, displays increased thermal stability. This is due to occurrence of a series of chemical reactions between organic and inorganic parts of the system with the new structure formation.

\subsection{Thermo-oxidative destruction of modified CG film}

Properties of modified gelatin films combine the properties of individual components and according to the DTG curves (Fig. 1 c; Fig. 2 a, curve 5) they combine properties of both CG and APU.

The first stage for sample 5 covers the same interval $\left(79-119^{\circ} \mathrm{C}\right.$ ) with a peak at $99{ }^{\circ} \mathrm{C}$ as for the original APU. Both samples display equal $E_{\text {act }}-69 \mathrm{~kJ} / \mathrm{mol}$. This similarity of the indices can be attributed to the dehydration process of composite films when heated. Although gelatin film is inherently more hydrophilic in comparison with polyurethane, the dispersions of anionic polyurethane brings the system ionic salt groups of the tertiary nitrogen atmosphere atom, which align their hydrophilicity. The second stage $\left(130-270^{\circ} \mathrm{C}\right)$ of thermo-oxidative destruction of modified gelatin films, as well as for the CG, is can be explained by the melting process. The beginning of the third stage of destruction $\left(294-354^{\circ} \mathrm{C}\right)$ is shifted by $50{ }^{\circ} \mathrm{C}$ to the right and proceeds with almost the same mass loss as the CG. Taking into account the large mass loss $(23.3 \%$ for stage) and increased $E_{\text {act }}-101 \mathrm{~kJ} / \mathrm{mol}$ for sample 5 (Table 3) in comparison with $\mathrm{CG}$, the expansion of crystallinity zone in modified CG can be assumed to be the result of the interaction of the active centers of $\mathrm{CG}$ and ionic centers of APU. Perhaps, at this degradation stage the processes of monotropic polymorphic transformations with formation of crystalline structure have occurred. Sufficiently high $E_{\text {act }}$ of thermal decomposition for sample 5 testifies to the destruction of much stronger structure, than the chromium tanned gelatin.

The temperature of destruction of the polyurethane component in modified CG (sample 5) is $414-449{ }^{\circ} \mathrm{C}$ that is close to that of APU, although the mass loss decreases in comparison with the original APU almost by 2 times (Table 3) and the effective activation energy increases by a factor of 2. Consequently, the thermal destruction of the polyurethane component is slower, with large energy consumption, which confirms the fact of chemical modification of the protein component with the anionic polyurethane. It can be assumed that during modification the redistribution of coordination and electrovalent bonds COO$\mathrm{Cr}-\mathrm{OOC}$ of protein is taking place forming the similar bonds COO-Cr-OOC of polyurethane with free active centers, thus creating conditions for the formation of a more heatresistant crystalline structure of the modified sample 5 $[18,19]$

The maximum rate of decomposition of the polyurethane component is $1.17 \mathrm{mg} / \mathrm{min}$, which is less than that of pure APU, but it is accompanied with greater mass loss. In comparison with APU, the peak of maximum decomposition rate of modified $\mathrm{CG}$ is shifted by $148^{\circ} \mathrm{C}$ toward higher temperatures (Fig. 2). As in the original APU, in a modified gelatin film at this stage the degradation of the polymer chain and intense oxidation of the intermediate products is occurring. The higher value of $E_{\text {act }}=330 \mathrm{~kJ} / \mathrm{mol}$ suggests some internal plasticization of the polymer with protein, which could result in mobility of partially segmented polymer chains and formation of more porous structure [20]. Also, at this stage an interaction of chromium compounds, released after the collapse of polypeptide chains, with the active groups of anionic polymer is possible, resulting in a gradual shift of the TG and DTG peaks (Fig. 1 c; Fig. 2 a, curve 5).

According to TG and DTG profiles and calculated indices, thermodestruction of modified CG films is similar to that of APU indicating the essential influence of the latter on chromium tanned gelatin due to their physico-chemical and chemical interactions. 


\section{CONCLUSIONS}

The thermal study of APU confirms their high thermal stability, resulting in high onset decomposition temperature with a small mass loss, and high activation energy of the process, which makes possible their use as film forming matter in compositions for leather finishing. The APU compositions with natural compounds increases their thermal stability both in air and in nitrogen atmosphere due to the formation of additional bonds between active groups of APU, protein and chromium tanned tanning agent as the result of chemical reactions between organic and inorganic parts with the new structure formation. This statement was confirmed by carried out earlier IR-spectral studies [21]. In addition to modified APU into chromium tanned gelatin, the thermal destruction of the latter becomes slower, with much higher energies, indicating the chemical modification of chromium tanned gelatin with anionic polyurethane. It allows to assume the same interactions with the derma surface during leather finishing with the use of APU.

\section{REFERENCES}

1. Bacardit, A., Canals, N., Cobos, M., Shendryck, A., Sole, O., Olle, L. Characterization and Evaluation of Four Types of Finish Topcoats Journal of the Society of Leather Technologists and Chemists 93 (4) 2009: pp. 130-140.

2. Kunts, M., Shlyk, G., Krivosheeva, N. Method of Finishing the Leather for Clothes Pat. 2160784 (Russia), MPK ${ }^{7}$ C 14 C 11/00, 13/00 Publ. 20.12.2000: Bul. 35.

3. Kovtunenko, O., Travinskaya, T. Compositions Based on Acrylate Copolymer and Collagen-comprising Product Book of Abstract IV Ukranian-Polish Scientific Conference 2006: pp. 94.

4. Kovtunenko, O., $\quad$ Zhuravskiyy, V., Kasyan, E., Gorbachov, A. Composition for Genuine Leather Dressing Pat. 69894 A (Ukraine), MPK ${ }^{7}$ C14 C11/00 Publ. 15.09.2004: Bul. 9.

5. Xiong, J., Zheng, Z., Jiang, H., Ye, S., Wang, $X$. Reinforcement of Polyurethane Composites with an Organically Modified Montmorillonite Composites 38 (1) 2007: pp. $132-137$.

6. Khachatrian, A., Markarian, S. Use of Silica-organic Compounds at Genuine Leather Dressing Kozhevennoobuvnaya Promyshlennost 4 2008: pp. 19-20.

7. Rabek, Ya. Experimental Methods in Polymer Chemistry. Mir, Moscow, 1983: pp. 479.
8. Broido, A. A Simple Sensitive Graphical Method of Treating Thermogravimetry Analyse Data Journal of Polymer Science A 7 (2) 1969: pp. 1761-1773.

9. Tang, K., Wang, F., Liu, J. Preliminary Studies on the Termal Degradation Kinetics of Cattlehide Collagen Fibres Journal of the American Leather Chemists Association 99 (10) 2004: pp. $401-409$.

10. Tang, K., Wang, F., Liu, J. Termal Degradation Kinetics of Sweat Soaked Cattlehide Collagen Fibres Journal of the American Leather Chemists Association $102(2)$ 2007: pp. 52-62.

11. Maffia, G., Seltzer, M., Cook, P., Brown, E. Collagen Processing Journal of the American Leather Chemists Association 99 (4) 2004: pp. 164-170.

12. Zhang, Z., Li, G., Shi, B. Physicochemical Properties of Collagen, Gelatin and Collagen Hydrolysate from Bovine Limed Split Wasters Journal of the Society of Leather Technologists and Chemists 1 (90) 2006: pp. 23-29.

13. Cot, J. An Imaginary Journey to the Collagen Molecule for a Better Understanding of Leather Waste Treatments Journal of the American Leather Chemists Association 99 (8) 2004: pp. 322-351.

14. Gaidau, C. Applicative Chemistry of Tanning Metallic Heterocomplexes. Benthan Science Publishers, Romania, 2013: pp. $25-34$.

15. Dorofeeva, I.B., Kosobutskii, V.A., Tarakanov, O.G. Physic-chemistry of Polyurethanes. Kiev, 1981: pp. 76-78.

16. Shufen, L., Zhi, J., Kaijun, Y. Studies on the Thermal Behavior of Polyurethanes Polymer Plastics Technology and Engineering 45 2006: pp. 95-108.

17. Bao, Y., Yang, Z., Ma, J. Tanning Mechanism of Vinyl Polymer/Montmorillonite Nanocomposite Tannage Journal of the Society of Leather Technologists and Chemists 4 (91) 2007: pp. $162-168$.

18. Bao, L., Lan, Y., Zhang, S. Anionic Polyuretan Microemulsion Leather Filling-retanning Agent Journal of the Society of Leather Technologists and Chemists 2 (91) 2007: pp. $73-81$.

19. D'Aquino, A., D'Elia, G., Naviglio, B., Seggiani, M., Tomaselli, M., Vitolo, S. Use of Sodium Silicate to Improve the Environmental Aspects of Traditional Chrome Tanning Journal of the American Leather Chemists Association 99 (1) 2004: pp. 26-37.

20. Prisacariu, C. Polyurethane Elastomers. Springer, Vienna, 2011: pp. $35-56$.

21. Kovtunenko, O.V., Kasyan, E.E., Ostapyuk, S.M. IRspectroscopic Study of Polyurethane Ionomers in Leather Dressing Bulletin of the Kyiv National University of Technologies and Design 4 2010: pp. 302-307. 